American Journal of Immunology 1 (4): 125-129, 2005

ISSN 1553-6203

(c) 2005 Science Publications

\title{
Isolation and Mutagenesis of Streptokinase Producing Bacteria
}

\author{
Thaer Taleb Abed Abdelghani, Adinarayana Kunamneni, Poluri Ellaiah \\ Pharmaceutical Biotechnology Division, Department of Pharmaceutical Sciences \\ Andhra University, Visakhapatnam - 530 003, India.
}

\begin{abstract}
Of $103 \beta$-haemolytic Streptococci (with haemolytic activity) in total were isolated from different samples of blood and biomass from infected throat, 47 isolates exhibited streptokinase (SK) activity. T3, identified as a new variant of Streptococcus equisimilis, was found to be excellent SK producer in submerged fermentation and was selected for strain improvement studies. This strain was mutagenized by UV and N-methyl-N'-nitro-N-nitroso guanidine (NTG). The isolation of mutants and the SK activity of selected mutants were described. The SK yield of the best UV mutant AUV10 was $120 \%$ higher than the wild strain (T3). Also, the SK yield of the best NTG mutant NUV7 was 146\% higher than the wild strain (T3). The results indicated that UV and NTG were effective mutagenic agents for strain improvement of S. equisimilis T3 for enhanced SK productivity.
\end{abstract}

Key words: Streptokinase (SK), screening, isolation, mutagenesis, bacteria

\section{INTRODUCTION}

A blood clot (thrombus) developed in the circulatory system can cause vascular blockage leading to serious consequences including death. A healthy hemostatic system suppresses the development of blood clots in normal circulation, but reacts extensively in the event of vascular injury to prevent blood loss. Outcomes of a failed hemostasis include stroke, pulmonary embolism, deep vain thrombosis and acute myocardial infraction. Pathologies involving a failure of hemostasis and the development of clot require clinical intervention consisting of intravenous administration of thrombolytic agents (Collen et al., 1988, Collen, 1990 and Francis and Marder, 1991; Banerjee et al., 2004). Streptokinase is one such agent. Other thrombolytic or fibrinolytic agents include urokinase and the tissue type plasminogen activator (tPA).

Numerous trails have been conducted to compare the clinical efficacy of recombinant tPA and streptokinase. Generally, these investigations have not revealed a clear preference for either drug. Streptokinase is as effective as recombinant tPA in treating acute myocardial infarction (Sherry and Marder, 1991), and it is certainly more cost-effective; however, its use is not risk free. In view of the relatively recent availability of the competing recombinant tPA, skepticism is being expressed about the continued viability of streptokinase therapy (Sane and Little, 1998 and Werf, 1999). Despite this, research on streptokinase continues, and it remains a vital affordable therapy especially in the world's poorer healthcare systems.

Streptokinase (SK) is an extracellular protein produced by many strains of $\beta$ - haemolytic streptococci (Tillet and Garner, 1933). It facilitates lyses of blood clots by activating the plasminogen, to the fibrinolytic enzyme, plasmin. The SK has been currently used in clinical medicine as a therapeutic agent in the treatment of acute myocardial infraction following coronary thrombosis (Ko et al., 1995; Banerjee et al., 2004).

The SK has been reported that Feldman (1974), increase in yield of the SK with strain H-46A. Malke and Ferretti (1984) used brain-heart infusion (BHI) medium and got good growth of $S$. equisimilis H-46A. Lee et al. (1997) achieved enhanced production and secretion of SK into extracellular medium by Escherichia coli.

The increasing potential of SK application promoted us to screen for newer streptokinaseproducing organisms. Also the exponential increase in the application of SK in various fields in the last few decades demands extension in both qualitative improvement and quantitative enhancement. Quantitative enhancement requires strain improvement and medium optimization for the overproduction of the enzyme, as the quantities produced by wild strains are usually too low. The spectacular success examples of strain improvement in industry are mostly attributed to the extensive application of mutation and selection. Hence, in the present work, an attempt was made to isolate streptokinase-producing bacteria and subjecting it to strain improvement by random mutagenesis (UV

Corresponding Author: Dr. Adinarayana Kunamneni, Department of Pharmaceutical Sciences, Andhra University, India, Tel: +91 891 2505519, Fax: ++91 8912755547 
irradiation and NTG (N-methyl- N'-nitro-N-nitroso guanidine) treatment) to enhance SK productivity.

\section{MATERIALS AND METHODS}

Screening and Isolation of Producing Streptococci: A total of nine samples were collected in sterile containers for the systematic screening of $\beta$-haemolytic Streptococci. The samples included blood and biomass from infected throat (Table 1).

The $\beta$-haemolytic Streptococci were isolated from different samples by plating on sheep blood agar medium. They can easily be distinguished on the plate from those of other bacteria as they form a clear zone of hydrolysis around the colonies.

In literature, several media have been suggested for the isolation of $\beta$-haemolytic Streptococci such as blood agar and sodium azide (Cruickshank, 1968); crystal violet blood agar, Todd Hewitt infusion broth and PNF medium (Collee et al., 1969). Pour plate method has been used in the present work for the isolation of Streptococci.

To $45 \mathrm{ml}$ of melted and cooled nutrient agar base (Hi-media, India) $\left(55^{\circ} \mathrm{C}\right)$, sterile sheep blood was added at $10 \%$ level. To this, $0.05 \mathrm{ml}$ of each test sample was mixed and poured into 6" petridishes and incubated at $37^{\circ} \mathrm{C}$ for $24 \mathrm{~h}$. The discrete colonies with clear hydrolysis zones were picked up, transferred into blood agar slants and incubated at $37^{\circ} \mathrm{C}$ for $24 \mathrm{hr}$. The microorganisms, which formed clear zones after incubation, were selected. The selected isolates were subjected for extracellular SK production by submerged fermentation.

Morphological and taxonomic characteristics of the promising isolated strain was examined by by Bergey's Manual of Determinative Bacteriology, 1974, Bergey's Manual of Systematic Bacteriology, 1992, Mackie and McCartney Practical Medical Microbiology (Collee et al., 1969), District Laboratory Manual Practice in Tropical Countries (Monica, 2000), Medical Microbiology (Cruickshank, 1968) and Laboratory Manual on Fundamental Principles of Bacteriology (Salle, 1948).

\section{Strain Improvement Studies:}

UV Irradiation: Strain improvement for the selected parent strain, was done by mutation and selection. The wild strain was subjected to UV irradiation. Mutation frequency was mentioned to be high when the survival rates were between 10 and $0.1 \%$. The dose survival curve was plotted for selecting the mutants between 10 and $0.1 \%$ rate.

The spore suspension of wild strain was prepared in phosphate buffer ( $\mathrm{pH}$ 8.0) and four ml quantities of the spore suspension were pipetted aseptically into sterile petri dishes of $80 \mathrm{~mm}$ diameter having a flat bottom. The exposure to UV light was carried out in a "Dispensing - Cabinet" fitted with TUP 40w Germicidal lamp which has about $90 \%$ of its radiation at 2540-2550 $\mathrm{A}^{0}$. The exposure was carried out at distance of $20.0 \mathrm{~cm}$ away from the center of the Germicidal lamp (UV light source) with occasional shaking. The exposure times were $0,2,4,6,8$ and 10 min. Each UV exposed cell suspension was stored in dark overnight to avoid photo reactivation, then was serially diluted in phosphate buffer and plated on PDA medium. The plates were incubated for $24 \mathrm{hr}$ at $37^{\circ} \mathrm{C}$ and the numbers of colonies in each plate were counted. Each colony was assumed to be formed from a single cell. A total of 15 colonies (designated as AUV1 to AUV15) were selected from the plates showing less than $1 \%$ survival rate (6 and 8 min UV exposure time) and tested for SK production. Among the selectants, the best UV mutant strain was used for further studies.

NTG Treatment: The NTG is considered to be a very effective mutagen (Adelberg et al., 1965 and CerdiaOlmedo and Hanawalt, 1968). Its action has been attributed to its decomposition products (CerdiaOlmedo and Hanawalt, 1968). The best UV mutant (AUV10) was used for NTG treatment. The spore suspension was prepared in the same manner as described earlier. To a $9 \mathrm{ml}$ of spore suspension, $1 \mathrm{ml}$ of sterile solution of NTG $(3 \mathrm{mg} / \mathrm{ml}$ in phosphate buffer) was added. The reaction was allowed to proceed. Samples were withdrawn from the reaction mixture at intervals of 30, 60, 90, 120, 150 and $180 \mathrm{~min}$ and immediately centrifuged for $10 \mathrm{~min}$ at $5000 \mathrm{rpm}$ and the supernatant solution was decanted. Cells were washed three times with sterile water and resuspended in $10 \mathrm{ml}$ of sterile phosphate buffer. The samples were serially diluted in the same buffer and plated over PDA as mentioned earlier. A total of 15 colonies (designated as NUV1 to NUV15) were selected from the plates showing less than $1 \%$ survival rate (120 and $150 \mathrm{~min}$ NTG treated spore suspension) and tested for SK production.

Shake Flask Fermentations: The growth of the isolate cultivated on nutrient agar slants was scrapped with 5 $\mathrm{ml}$ of sterile distilled water and transferred into $250 \mathrm{ml}$ Erlenmeyer flask containing $45 \mathrm{ml}$ of production medium (Baewald, 1975) [(g/L): glucose, 5.0; yeast autolyzate, 5.0; $\quad \mathrm{KH}_{2} \mathrm{PO}_{4}, \quad 2.5 ; \quad \mathrm{KH}_{2} \mathrm{PO}_{4}, \quad 2.5$; $\mathrm{MgSO}_{4} .7 \mathrm{H}_{2} \mathrm{O}, 0.4 ; \mathrm{NaHCO}_{3}, 1.0 ; \mathrm{CH}_{3} \mathrm{COONa} .3 \mathrm{H}_{2} \mathrm{O}$, 1.0; $\mathrm{FeSO}_{4} .7 \mathrm{H}_{2} \mathrm{O}, 0.02$ and $\mathrm{MnCl}_{2} .4 \mathrm{H}_{2} \mathrm{O}, 0.02$ with $\mathrm{pH}$ 7.5.] in $250 \mathrm{ml}$ Erlenmeyer flask. The flasks were incubated at $37^{\circ} \mathrm{C}$ for $24 \mathrm{hr}$ in a shaker incubator (120 $\mathrm{rpm})$. The culture broth was then filtered and the clear filtrate was used as the crude enzyme source.

SK Assay: The SK activity was determined using modified Holmstrom method (Holmstrom, 1965). One 
unit (U) is defined as quantity of enzyme that will liquefy a standard clot of fibrinogen, plasminogen and thrombin at $\mathrm{pH} 7.5$ at $37^{\circ} \mathrm{C}$ in $18 \mathrm{~h}$. All the experiments were conducted in triplicate.

\section{RESULTS}

About 103 Streptococci (with haemolytic activity) in total were isolated from the above 9 samples. The distribution of Streptococci in different samples is shown in Table 1. The isolates were pooled together and cultures, which appeared identical to the naked eye, were eliminated. All the isolates were tested for their $\beta$ haemolytic activity on PNF selective medium. About $47 \beta$-haemolytic positive isolates were obtained (identical hydrolysis zone). Among these, 20 isolates showed moderate to good haemolytic activity. These 20 isolates (human source) were selected to study their SK activities. Among the 20 active isolates, isolate T3 gave highest SK activity $(681 \mathrm{U} / \mathrm{ml})$. As such, this isolate (T3) was subsequently selected for the taxonomic studies.

Table 1: Sources of samples (distribution of Streptococci in different samples)

\begin{tabular}{lclll}
\hline S.No & Sample No. & Source of culture & Disease & No. of isolates \\
& & & & \\
\hline 1 & HB1 & Human blood & Septicaemia & 9 \\
2 & HB2 & Human blood & Septicaemia & 10 \\
3 & HB3 & Human blood & Septicaemia & 14 \\
4 & HT1 & Human throat & Acute tonsillitis & 11 \\
5 & HT2 & Human throat & Acute tonsillitis & 10 \\
6 & HT3 & Human throat & Scarlet fever & 12 \\
7 & HB4 & Human blood & Scarlet fever & 13 \\
8 & SB5 & Sheep blood & Scarlet fever & 11 \\
9 & SB6 & Sheep blood & Scarlet fever & 13 \\
& & & Total & 103 \\
\hline
\end{tabular}

Proper identification and characterization of microorganisms is a very important because it expands the scope for exploitation of industrially important products. To establish the novelty or otherwise of the present isolates with those of reported in the literature, the various morphological, cultural and biochemical characteristics of the isolated organisms were compared with the descriptions of the numerous Streptococcus species cited in the literature. Also Lancefield grouping was carried out. The literature survey includes Bergey's Manual of Systematic Bacteriology (1992), Bergey's Manual of Determinative Bacteriology (1974), Mackie and McCartney Practical Medical Microbiology (Collee et al., 1969), District Laboratory Practice in Tropical Countries (Monica, 2000), Medical Microbiology (Cruickshank, 1968) and Laboratory Mannual on Fundamental Principles of Bacteriology (Salle, 1948) Biological and Microbiological abstracts and all other relevant journals.
The characteristics of our isolate T3 were compared with that of the reference cultures. The reference cultures used are: H46A strain, a group C Streptococci procured from Dr. Malke, Germany and NZ131, a group A Streptococci procured from Dr. Ferretti, Oklahoma University, USA.

The cultural characteristics, physiological and biochemical properties, sugar fermentation, growth in different media and resistance to various inhibitors are shown in Table 2.

The most important characteristics of the strain T3 are summarized as follows: The cells are spherical in shape, with moderately long chains in liquid media. There are no endospores or pellicle formation in broth media. They are non-motile and gram-positive. There was no growth at a temperature of $10^{\circ}$ or $45^{\circ} \mathrm{C}$, at initial pH 9.6 and heating the cells at $60^{\circ} \mathrm{C}$ for $30 \mathrm{~min}$. Growth was not observed in media containing $0.1 \%$ methylene blue, $6.5 \%$ sodium chloride and $40 \%$ bile. Good growth was observed in media containing sodium azide or in crystal violet blood agar medium and potassium tellurite. The strain exhibited negative litmus milk reduction test. It showed a positive $\beta$-haemolysis and PNF tests. The minimum inhibitory concentration (MIC) of the strain with benzyl penicillin was $0.02 \mu \mathrm{g} / \mathrm{ml}$. The strain exhibited negative CAMP test. The isolate did not hydrolyze gelatin, hippurate and esculin. It hydrolyzed starch and arginine. It exhibited negative tests of pyruvate fermentation, VogesProskauer (acetoin production), catalase and hydrogen sulphide production. The strain showed methyl red and nitrate reduction tests positive.

The final $\mathrm{pH}$ in glucose fermentation was 4.7 and no gas was formed. The acid formation was positive from salicin, trehalose, cellobiose, glycerol, galactose, fructose, xylose, mannose, sucrose, maltose and glucose. The acid formation was negative from inulin, lactose, mannitol, raffinose, ribose, sorbitol, melibiose, arabinose, inositol, erythritol, dulcitol, dextrin, adonitol, rhamnose, soluble starch and potato starch.

The wild strain of $S$. equisimilis T3 was subjected to strain improvement programme with a view to obtain increased SK production and to achieve greater stability of the organism. The first method chosen was UV irradiation.

The selected mutants were provided with the code number AUV1 to AUV15 and these mutants were tested for their SK producing capabilities (Table 3). The results indicated that among UV mutants, AUV10 was found to be the highest SK producer $(821 \mathrm{U} / \mathrm{ml})$ and it was $120 \%$ higher yield over the wild strain $(681 \mathrm{U} / \mathrm{ml})$. The mutant, AUV10 was selected for further strain improvement studies using NTG.

The selected UV mutant, AUV10 was subjected to NTG treatment. A total of 15 mutants were selected, and they were provided with the code numbers NUV1 to NUV15. These were evaluated for their SK production capacities (Table 3). The results indicated that the mutant NUV7 was the highest SK yielding strain $(996 \mathrm{U} / \mathrm{ml})$. Thus the NTG treatment results a mutant that produced $146 \%$ higher yield of SK over the wild strain $(681 \mathrm{U} / \mathrm{ml})$, which is a significant increase of yield. 
Am. J. Immunol. 1 (4): 125-129, 2005

Table 2: Morphological, metabolic, biochemical and sugar fermentation tests of the isolate $\mathrm{T} 3$ and reference cultures

\begin{tabular}{|c|c|c|c|c|c|c|c|c|c|}
\hline Morphological and metabolic tests & $\mathrm{T} 3$ & $\mathrm{H} 46 \mathrm{~A}$ & NZ 131 & Group G & Sugar fermentation tests & $\mathrm{T} 3$ & $\mathrm{H} 46 \mathrm{~A}$ & NZ 131 & Group G \\
\hline Haemolysis & + & + & + & + & Inulin & - & - & - & + \\
\hline PNF test & + & + & + & + & Lactose & - & + & + & + \\
\hline Shape of the cells & $\mathrm{S}$ & $S$ & $\mathrm{~S}$ & $\mathrm{O}$ & Mannitol & - & - & - & - \\
\hline Endospores & - & - & - & - & Raffinose & - & - & - & - \\
\hline Motility & - & - & - & - & Ribose & - & + & - & + \\
\hline Gram-staining & + & + & + & + & Salicin & + & + & + & - \\
\hline Growth at & & & & & Sorbitol & - & - & - & - \\
\hline $10^{\circ} \mathrm{C}$ & - & - & - & - & Trehalose & + & + & + & + \\
\hline $45^{\circ} \mathrm{C}$ & - & - & - & - & Cellobiose & + & + & + & - \\
\hline pH 9.6 & - & - & - & - & Melibiose & - & - & - & - \\
\hline Heat tolerance at $60^{\circ} \mathrm{C}$ for $30 \mathrm{~min}$ & - & - & - & - & Glycerol & + & + & - & + \\
\hline Growth in media containing & & & & & Arabinose & - & - & - & No \\
\hline Methylene blue ( $0.1 \%$ in milk) & - & - & - & - & Inositol & - & - & - & - \\
\hline Sodium chloride $(6.5 \%)$ & - & - & - & - & Galactose & + & + & + & No \\
\hline Bile salt $(40 \%)$ & - & - & - & - & Erythritol & - & - & - & No \\
\hline Potassium tellurite & + & + & + & + & Dulcitol & - & - & - & No \\
\hline Growth in & & & & & Dextrin & - & - & + & No \\
\hline Sodium azide medium & G & M & G & No & Adonitol & - & - & - & No \\
\hline Crystal violet blood agar & $\mathrm{G}$ & M & $\mathrm{G}$ & No & Rhamnose & - & - & - & No \\
\hline Litmus milk reduction test & - & - & - & - & Soluble starch & - & - & - & No \\
\hline MIC (penicillin $\mathrm{G}, \mu \mathrm{g} / \mathrm{ml}$ ) & 0.02 & 0.04 & 0.006 & 0.004-0.006 & Potato starch & - & - & - & No \\
\hline \multirow[t]{2}{*}{ cAMP test } & - & - & - & - & Fructose & + & + & + & No \\
\hline & & & & & Xylose & + & + & + & No \\
\hline Biochemical tests: & & & & & Mannose & + & + & + & No \\
\hline Hydrolysis of & & & & & Sucrose & + & + & + & + \\
\hline Gelatin & - & - & \pm & - & Maltose & + & + & + & + \\
\hline Starch & + & \pm & - & - & Glucose & + & + & + & + \\
\hline Hippurate & - & - & - & - & Final $\mathrm{pH}$ in gluose broth & 4.7 & 4.9 & 5.5 & No \\
\hline Esculin & - & \pm & \pm & \pm & & & & & \\
\hline Arginine & + & + & + & + & & & & & \\
\hline Pyruvate fermentation & - & - & - & - & & & & & \\
\hline Voges-Proskauer & - & - & - & - & & & & & \\
\hline Methyl red & + & + & + & + & & & & & \\
\hline Hydrogen sulphide & - & - & - & - & & & & & \\
\hline Catalase & - & - & - & - & & & & & \\
\hline Nitrate reduction & + & + & + & + & & & & & \\
\hline Lancefield grouping & $\mathrm{C}$ & $\mathrm{C}$ & A & $\mathrm{G}$ & & & & & \\
\hline
\end{tabular}

G: Good growth, M: Moderate growth, No: Not reported, S: Spherical, O: Oval, +: Positive reaction, -: Negative reaction

Table 3: UV mutants and NTG treated selectants from AUV 10 and their SK activity

UV mutants SK activity (U/ml) $\quad$ NTG mutants $\quad$ SK activity (U/ml)

\begin{tabular}{llll}
\hline AUV1 & $462.0 \pm 12.1$ & NUV1 & $673.0 \pm 7.6$ \\
AUV2 & $516.0 \pm 15.0$ & NUV2 & $668.0 \pm 6.3$ \\
AUV3 & $458.0 \pm 14.0$ & NUV3 & $684.0 \pm 6.9$ \\
AUV4 & $503.0 \pm 14.4$ & NUV4 & $717.0 \pm 6.1$ \\
AUV5 & $402.0 \pm 13.9$ & NUV5 & $740.0 \pm 7.3$ \\
AUV6 & $494.0 \pm 15.1$ & NUV6 & $469.0 \pm 5.9$ \\
AUV7 & $635.0 \pm 16.2$ & NUV7 & $996.0 \pm 8.5$ \\
AUV8 & $576.0 \pm 16.1$ & NUV8 & $772.0 \pm 9.2$ \\
AUV9 & $580.0 \pm 16.3$ & NUV9 & $597.0 \pm 6.0$ \\
AUV10 & $821.0 \pm 17.4$ & NUV10 & $663.0 \pm 7.1$ \\
AUV11 & $404.0 \pm 16.0$ & NUV11 & $499.0 \pm 6.3$ \\
AUV12 & $678.0 \pm 15.7$ & NUV12 & $677.0 \pm 7.4$ \\
AUV13 & $583.0 \pm 16.1$ & NUV13 & $467.0 \pm 5.7$ \\
AUV14 & $434.0 \pm 13.5$ & NUV14 & $366.0 \pm 3.5$ \\
AUV15 & $392.0 \pm 12.3$ & NUV15 & $716.0 \pm 3.4$ \\
T3 (Wild strain) $681.0 \pm 16.4$ & & \\
& & &
\end{tabular}

\section{DISCUSSION}

A total of 103 isolates were obtained from nine samples of blood and biomass from infected throat. Of them, 20 isolates showed moderate to good SK activity and the strain T3, which gave maximum enzyme activity, was selected for detailed taxonomical studies.

A detailed survey of the literature indicated that our isolate T3 belongs to Streptococci group C. The data indicated that our isolate is closure to $S$. equisimilis. A detailed comparison of our isolate was made to establish its novelty or otherwise. The data is presented in Table 2. However, some significant qualitative and quantitative differences could be noticed. Our isolate T3 differed from the reference culture in the following aspects: Good growth was observed for our isolate $\mathrm{T} 3$ on sodium azide and crystal violet blood agar media while moderate growth was observed for the reference culture on the same media. The MIC against benzyl penicillin of our isolate was found to be $0.02 \mu \mathrm{g} / \mathrm{ml}$ while it was $0.04 \mu \mathrm{g} / \mathrm{ml}$ for reference. Regarding the biochemical reactions, our isolate has a slight amylolytic activity while reference culture showed no amylolytic activity. Esculin hydrolysis was negative for our isolate while it was delay activity for reference. Reference culture produced acid from lactose and ribose while our isolate did not 
produce. In view of these significant differences, it is proper to consider our isolate T3 is a new variant of $S$. equisimilis.

The wild strain of $S$. equisimilis was subjected to strain improvement studies. From the results (Table 3 ), it is evident that UV and NTG were effective mutagenic agents for strain improvement of $S$. equisimilis T3. By employing these techniques, a superior mutant (NUV7) with a productivity of $146 \%$ (681 to $996 \mathrm{U} / \mathrm{ml}$ ) higher than that of the wild strain was obtained.

\section{CONCLUSIONS}

The results revealed that UV and NTG were effective mutagenic agents for strain improvement of $S$. equisimilis T3 for enhanced SK productivity. It is hoped that the high yielding mutant strain of the isolate S. equisimilis T3 can be exploited commercially for large scale industrial production of SK. Also future studies will test SK in vivo, and the cloning, sequencing, and expression of the SK gene from chromosomal DNA of $S$. equisimilis strain T3 is proceeding.

\section{ACKNOWLEDGEMENTS}

The authors are thankful to Andhra University, Visakhapatnam, India and Council of Scientific \& Industrial Research (CSIR), New Delhi, India, for providing financial support to carryout this work and awarding a senior research fellowship (Award No. 9/2 (454)/2k2, EMR.I) to Dr. Adinarayana Kunamneni.

\section{REFERENCES}

1. Adelberg, E.A., Mandel, M., Chen, G.C.C., 1965. Optimal conditions for mutagenesis by $\mathrm{N}-$ methyl-N-nitro-N-nitroso guanidine in Escherichia coli K12. Biochem. Biophys. Res. Commun. 18, 788-795

2. Baewald, G., Mayer, G., Heikel, R., Volzke, K.D., Roehlig, R., Decker, K.L., Koehler, W. and Gerlach, D., 1975. Fermentative production of Streptococcus metabolites, especially streptokinase. German patent DD 111096

3. Banerjee, A., Chisti, Y., Banerjee, U.C., 2004. Streptokinase - a clinically useful thrombolytic agent. Biotechnol. Adv. 22, 287-307

4. Cerda-Olmedo, E., Hanawalt, P.C., 1968. Diazomethane as the active agent in nitrosoguanidine mutagenesis and lethality. Mol. Gen. Genet. 101, 191-202

5. Collee, J.G., Fraser, A.G., Marmion, B.P., Simmons, A., 1969. Mackie and McCartney Practical Medical Microbiology, $14^{\text {th }}$ ed. Churchill Livingstone, New York
6. Collen, D., 1990. Coronary thrombolysis: streptokinase or recombinant tissue-type plasminogen activator?. Ann. Intern. Med. 112, 529-538

7. Collen, D., Stump, D.C., Gold, H.K., 1988. Thrombolytic therapy. Annu. Rev. Med. 39, 405-423

8. Cruickshank, R., 1968. Medical Microbiology, $11^{\text {th }}$ ed. E. and S. Livingstone Ltd., Edinburgh, UK

9. Feldman, L.J., 1974. Streptokinase Manufacture. German patent DE 2354019

10. Francis, C.W., Marder, V.J., 1991. Fibrinolytic therapy for venous thrombosis. Prog. Cardiovasc. Dis. 34 , 193-204

11. Holmstrom, B., 1965. Streptokinase assay on large agar diffusion plates. Acta Chem. Scand. 19, 1949-1954

12. Ko, J.H., Park, K., Kim, I.C., Lee, S.H., Byun, S.M., 1995. High level expression and secretion of streptokinase in Escherichia coli. Biotechnol. Lett. 17, 1019-1024

13. Lee, S.H., Kim, I.C., Bae, K.H., Byun, S.M., 1997. Enhanced production and secretion of streptokinase into extracellular medium in Escherichia coli by removal of 13 N-terminal amino acids. Biotechnol. Lett. 19, 151-154

14. Malke, H., Ferreti, J.J., 1984. Streptokinase: cloning, expression and excretion by E. coli. Proc. Natl. Acad. Sci. 81, 3557-3561

15. Monica, C., 2000. District Laboratory Practice in Tropical countries, Vol. II, Cambridge University Press, Cambridge, UK

16. Salle, A.J., 1948. Laboratory Mannual on Fundamental Principles of Bacteriology, $3^{\text {rd }}$ ed. McGraw-Hill Book Company, INC, London

17. Sane, D.C., Little, W.C., 1998. Is time running out on streptokinase?. J. Am. Coll. Cardiol. 31, 780-782

18. Sherry, S., Marder, V.J., 1991. Streptokinase and recombinant tissue plasminogen activator (rtPA) are equally effective in treating acute myocardial infarction. Ann. Intern. Med. 114, 417-423

19. Tillet, W.S., Garner, R.L., 1933. Fibrinolytic activity of hemolytic Streptococci. J. Exp. Med. 58, 485-491

20. Werf, F.V.D., 1999. Streptokinase...never again. Eur. Heart J. 20, 1215 